\title{
A Trade-Off for Frequency -Voltage Dependence of RF MEMS Switch
}

\author{
Mazhar B.Tayel \\ Prof. Dr. \\ Emeritus Professor, Faculty of Engineering
}

\author{
Ahmed Khairy Mahmoud \\ PHD student \\ Emeritus Professor, Faculty of Engineering
}

\begin{abstract}
This article introduced Trade-Off is taken as a new measure for MEMS switching to select the most probable frequency voltage dependence for cantilevered beam RF MEMS switches. The switching voltage of the mentioned structures for MEMS switches is determined and analyzed at different geometrical parameters. The results investigate the geometrical parameters of the eight MEMS structures that control the switching voltage to achieve a maximum frequency response for the switch at lower driving voltage.
\end{abstract}

\section{Keywords}

MEMS Switches, Trade-Off, RF MEMS

\section{INTRODUCTION}

The use of electrostatic MEMS switches is attractive because of its advantages, such as very low power consumption and high isolation. However, MEMS switches have their share of problems, such as, high driving voltage, relatively low speed and low power handling. In recent years many efforts have been done to solve these problems, e.g., decreasing the air gap between the fixed plate and the beam [1-10]. Another method is to increase the electrostatic area or decreasing the spring constant of the beam [11]. The most omnipresent structures in the MEMS area are cantilever beams. These cantilevers are generally made out of silicon $(\mathrm{Si})$, silicon nitride $(\mathrm{SiN})$ or polymers [12]. MEMS technology has generated a significant amount of interest in the government and business sectors. This interest is happening due to the potential performance and cost advantages with micro-scale devices fabricated based on a silicon processing technology [14]. Many previous researches focus on RF MEMS switch, which presents a good performance at microwave frequency. This result an increasing use of RF MEMS switches for telecommunication purpose in the last ten years. However, there are still some available improvement in RF MEMS switch to enhance its performance such as switching speed, loss, isolation value and the consumption of actuation voltage. This paper purposes to improve the performance of RF MEMS series switch for better performance in terms of voltage actuation, loss and isolation. A low voltage of MEMS switch is desirable because it will make it more convenient to be embedded into real applications [13].In this paper we try to design new geometrical structure, parameters of the electrostatic area of the gap that control the switching voltage to achieve a maximum frequency response for the switch at lower driving voltage and beams length.

\section{NODAL ANALYSIS APPROCH}

SUGAR [14], is a collection of Matlab routines which implements a nodal analysis to Micro Electro-Mechanical Systems (MEMS) simulation. A wide variety of planner electromechanical systems can be simulated. SUGAR creates individual stiffness, mass, and damping matrices for each structural block. The equation of motion describing the dynamics of the entire system can be expressed in a familiar form [5],

$$
M . \ddot{q}+C . \dot{q}+K . q=F
$$

Where $\mathrm{M}, \mathrm{C}, \mathrm{K}$ are the mass, damping, and stiffness matrices respectively. The nodal displacement $\mathrm{q}$ is

$$
\{q\}=\left\{x_{1} y_{1} \theta_{1} \ldots \ldots x_{N} y_{N} \theta_{N}\right\}
$$

The q Matrix is $1 \mathrm{x} 3 \mathrm{~N}$ column vector and $\mathrm{N}$ is the number of nodes. $\mathrm{F}$ is the applied driving force.

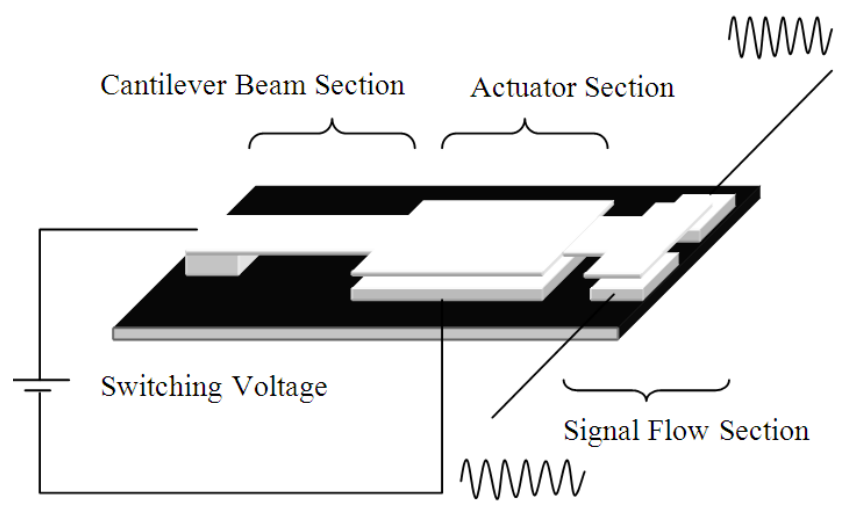

Figure .1. The Structure of Cantilever type MEMS switch.

\subsection{Static Analysis}

Static analysis attempts to find the equilibrium state for MEMS device with coupled energy domains [6]. These domains include mechanical forces, electrostatic forces due to a voltage from a circuit, forces due to thermal stress ...etc. The equilibrium position due to constant mechanical forces and voltages are calculated according to [7],

$$
K . q-F=0
$$

Solving equation (2) using Newton Raphson method, the initial guess $\left\{q_{o}\right\}$ is taken which is sufficiently near a root, then approaches the solution by iteration. Iteration proceeds until certain tolerance is satisfied,

$$
\left\|\left\{q_{n+1}\right\}-\left\{q_{n}\right\}\right\|<\xi
$$

where $\xi$ is the tolerance 


\subsection{Steady State Analysis}

In the steady state analysis the following equation is solved [18-25],

$$
M . \ddot{q}+C . \dot{q}+K . q=a_{i} \cos \left(w t+\beta_{i}\right)
$$

Where $a_{i} \cos \left(w t+\beta_{i}\right)$ is the sinusoidal external excitation. The solution of this equation is the real part of the following complex equation,

$$
M . \ddot{z}+C . \dot{z}+K . z=\beta_{i} e^{j w t}
$$

where

$$
\beta_{i}=a_{i}\left(\cos \beta_{i}+j \sin \beta_{i}\right)
$$

A particular solution of equation (4) is,

$$
Z=\{V\} e^{j w t}
$$

where $\mathrm{V}$ is a complex vector that contains the magnitude information of the system response. Substituting equation (5) into (4) to get,

$$
-\omega^{2} . M+j . \omega C+K . V=\{B\}
$$

Once equation (6) is solved, the magnitude and phase response for each node is evaluated. The steady state vibration of the structure can be investigated.

\section{3-Resonant frequency}

The moving parts in mechanical switches have resonant frequencies that can be modeled in terms of their effective spring constants and resonating mass. At this frequency, the potential energy and the kinetic energy tend to resonate. This frequency limits the maximum rate at which the switch can be toggled, but this virtually has no bearing on the frequency of the actual RF signals the switch carries. In electrical circuits, resonance occurs when the reactance of an inductor balances with the reactance of the capacitance for a given frequency. In a resonant circuit, when it is in series resonance, the current will be at a maximum, offering a minimum impedance and vice versa in parallel resonance. [2]

The spring constant can be written as

$$
K=16 E W\left(\frac{t}{L}\right)^{3}
$$

where $\mathbf{E}$ is the Young's modulus, and $\mathbf{W}, \mathbf{L}, \mathbf{t}$ are the width, length and thickness of the beam, respectively.

The cantilever's mechanical resonant frequency is:

$f_{o}=1.03 \sqrt{\frac{E}{\rho}} * \frac{h}{l^{2}}$

$\mathbf{E}$ young's modules , $\boldsymbol{\rho}$ is the mass density polysilicon, $\mathbf{h}$ beam thickness, $\mathbf{l}$ beam length

\subsection{The Switch Modeling}

The cantilever type MEMS switch shown in figure 1 is modeled as anchor, cantilever beam section, actuator section, signal flow section, and two isolated beams for signal line. The switching beam is electrically isolated from the upper plate of the gap. The structure of the cantilever type MEMS switch is simulated under applied voltage $\mathrm{V}$ between the two plates of the electrostatic gap. The displacement of the switching beam at node off the gap is calculated. The voltage is tuned to satisfy the switching-on between the two signal line beams. This voltage is called threshold voltage Vth. It is calculated at different selected geometrical parameters of the structure. Figure 2 shows the reflection of choice of different beam lengths and widths on the threshold voltage. The results show that at low values of beam widths the threshold voltage is lower than that at higher values, but almost the threshold voltage decreases with increasing the beam length. Figure 3 shows the reflection of choice of different beam lengths and widths on the threshold voltage, From figure 3, it is notice that the threshold voltage is increased more than double of its value at the highest values of beam thickness. This proposes the lower values of beam thickness to decrease the threshold voltage required for switching on. Figure 4 presents the effect of electrostatic gap length switch.

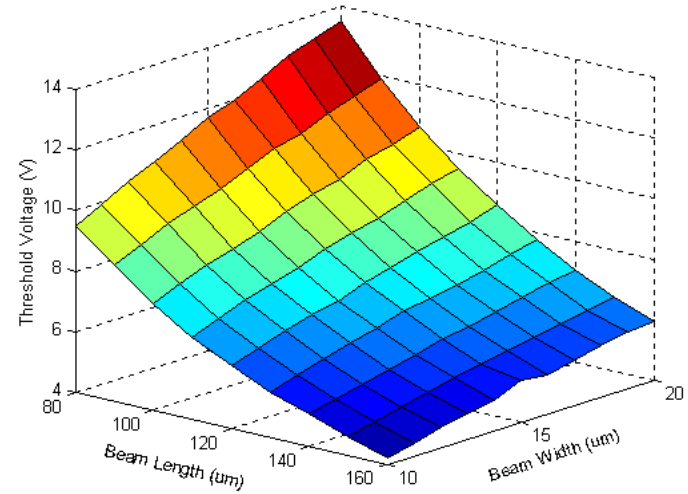

Figure. 2. The threshold voltage vs. beam length at different values of beam widths.

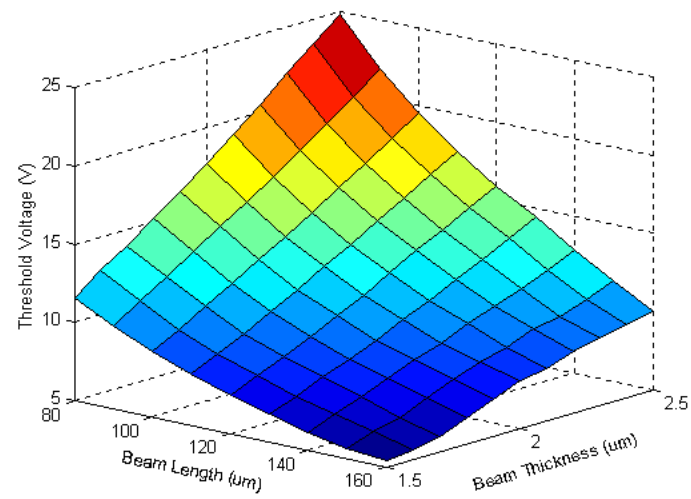

Figure. 3. The threshold voltage vs. beam length at different values of beam thickness.

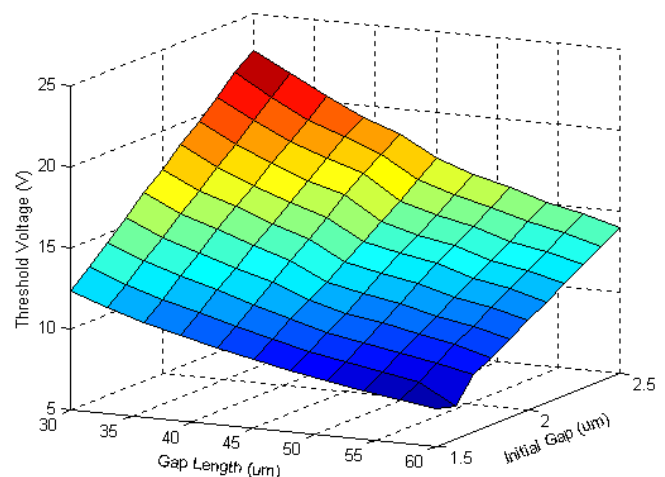

Figure. 4. The threshold voltage vs. gap length at different values of air gap thickness. 
It is useful to use the lower values of air gap thickness and higher values of gap length to satisfy a lower threshold voltage Vth. Figure 5 shows the first used structure from the RF MEMS switch. When a certain amount of voltage is applied between gap and the cantilever, electrostatic force is created and will pull the cantilever down from the arm of anchor and complete the RF signal path at down-state. Short circuit occurred between the two terminals of the RF transmission line has made the RF signal can pass through and transmitted. The cantilever is then back to the original position once the voltage supply is removed and hence disconnects the transmission of RF signals. The material and geometrical parameters of the first structure is illustrated in table 1. The second structure shown in Figure 6, uses two supported anchors extend two cantilever beams connected with the actuator area. The second structure dimension is illustrated in table 2. The schematic in Figure 7 shows the third structure with two parallel beams and two gaps and its parameters illustrated in table 3 . The fourth structure is shown in Figure 8 with two beams and one gap and its parameters illustrated in table 4 . Figure 9 shows the fifth structure with one main beam and six gaps and its parameters illustrated in table 5 .

\section{SIMULATION RESULTS}

Five cantilever RF MEMS switches structures are designed, simulated and optimized for minimum driving voltage while maintain maximum switching frequency. Table (6) illustrate the structures behavior demonstrate the driving voltage, displacement, frequency, and the actuator electrostatic area. The first structure record the minimum driving voltage of $4.2 \mathrm{~V}$ with $1.03 \mathrm{GHz}$ switching frequency. The fourth structure record a maximum frequency response of $6.65 \mathrm{GHz}$ with $6.6 \mathrm{~V}$ of the driving voltage. These two structures are suitable for radar antenna applications.

Table (1): The Material And Geometrical Parameters For Cantilever Type Mems Switch

\begin{tabular}{|c|c|}
\hline Parameter & Value \\
\hline Material & Polysilicon \\
\hline Poisson's ratio & 0.3 \\
\hline Young's modulus & $1.65 \mathrm{E} 11 \mathrm{~N} / \mathrm{m}^{2}$ \\
\hline Sheet resistance & $20 \Omega / \square$ \\
\hline \multicolumn{2}{|l|}{ Anchor } \\
\hline Length & $20 \mu \mathrm{m}$ \\
\hline Width & $30 \mu \mathrm{m}$ \\
\hline Thickness & $8 \mu \mathrm{m}$ \\
\hline \multicolumn{2}{|l|}{ Beam } \\
\hline Length (L) & $80: 160 \mu \mathrm{m}$ \\
\hline Width (w) & $15 \mu \mathrm{m}$ \\
\hline Thickness (h) & $1.5: 2.5 \mu \mathrm{m}$ \\
\hline \multicolumn{2}{|l|}{ Gap } \\
\hline Length $\left(\mathrm{G}_{\mathrm{L}}\right)$ & $30: 60 \mu \mathrm{m}$ \\
\hline Width $\left(\mathrm{W}_{\mathrm{G}}\right)$ & $30 \mu \mathrm{m}$ \\
\hline Upper plate thick. & $1.5 \mu \mathrm{m}$ \\
\hline Lower plate thick. & $1.5 \mu \mathrm{m}$ \\
\hline Air gap thick. & $1.5: 2.5 \mu \mathrm{m}$ \\
\hline \multicolumn{2}{|l|}{ Switching beam } \\
\hline Length $\left(\mathrm{L}_{\mathrm{S}}\right)$ & $75 \mu \mathrm{m}$ \\
\hline Width & $30 \mu \mathrm{m}$ \\
\hline
\end{tabular}

\begin{tabular}{|c||c||}
\hline Thickness & $1.5 \mu \mathrm{m}$ \\
\hline \hline Signal line beam & $30 \mu \mathrm{m}$ \\
\hline Length & $90 \mu \mathrm{m}$ \\
\hline Width & $7 \mu \mathrm{m}$ \\
\hline Thickness & \\
\hline
\end{tabular}

Table (2) The second structure Parameters

\begin{tabular}{|c|c|c|c|c|c|}
\hline $\begin{array}{r}\text { Paramete } \\
\mathrm{r}\end{array}$ & $\begin{array}{c}\text { Beam } \\
\text { Angl } \\
\mathrm{e}\end{array}$ & $\begin{array}{c}\text { gap } \\
\text { Lengt } \\
\mathrm{h}\end{array}$ & $\begin{array}{c}\text { gap } \\
\text { width }\end{array}$ & $\begin{array}{c}\text { Beam } \\
\text { width }\end{array}$ & $\begin{array}{c}\text { Extende } \\
\mathrm{d} \text { Beam } \\
\text { length }\end{array}$ \\
\hline 2 & $45^{\circ}$ & $50 \mu \mathrm{m}$ & $\begin{array}{c}45 \\
\mu \mathrm{m}\end{array}$ & $\begin{array}{c}15 \\
\mu \mathrm{m}\end{array}$ & $45 \mu \mathrm{m}$ \\
\hline 3 & $90^{\circ}$ & $45 \mu \mathrm{m}$ & $\begin{array}{c}45 \\
\mu \mathrm{m}\end{array}$ & $\begin{array}{c}10 \\
\mu \mathrm{m}\end{array}$ & $60 \mu \mathrm{m}$ \\
\hline 4 & $45^{\circ}$ & $45 \mu \mathrm{m}$ & $\begin{array}{c}45 \\
\mu \mathrm{m}\end{array}$ & $\begin{array}{c}10 \\
\mu \mathrm{m}\end{array}$ & $100 \mu \mathrm{m}$ \\
\hline 5 & $90^{\circ}$ & 100 & $\begin{array}{c}100 \\
\mu \mathrm{m}\end{array}$ & $\begin{array}{c}10 \\
\mu \mathrm{m}\end{array}$ & $100 \mu \mathrm{m}$ \\
\hline 6 & $90^{\circ}$ & $50 \mu \mathrm{m}$ & $\begin{array}{c}30 \\
\mu \mathrm{m}\end{array}$ & $\begin{array}{c}10 \\
\mu \mathrm{m}\end{array}$ & $150 \mu \mathrm{m}$ \\
\hline
\end{tabular}

The simulation results compared to previous MEMS switches design and show acceptable results.

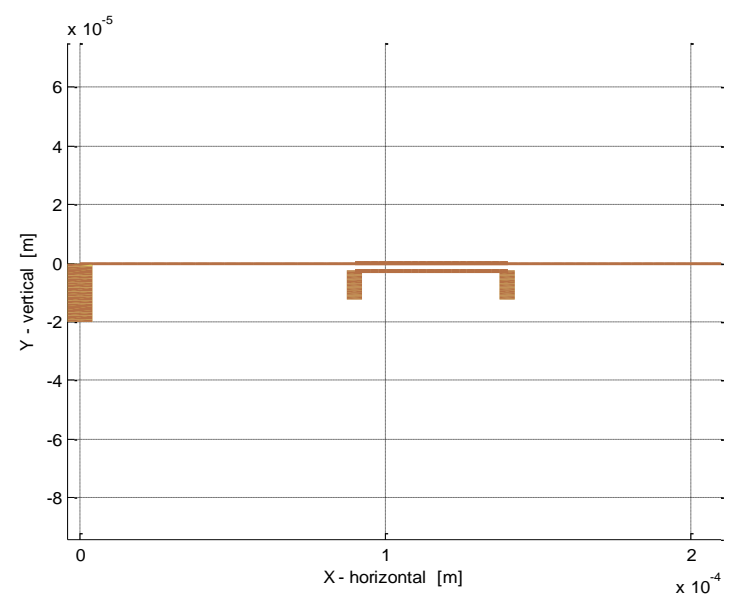

Figure. 5. Model 1 of the cantilever type MEMS switch.

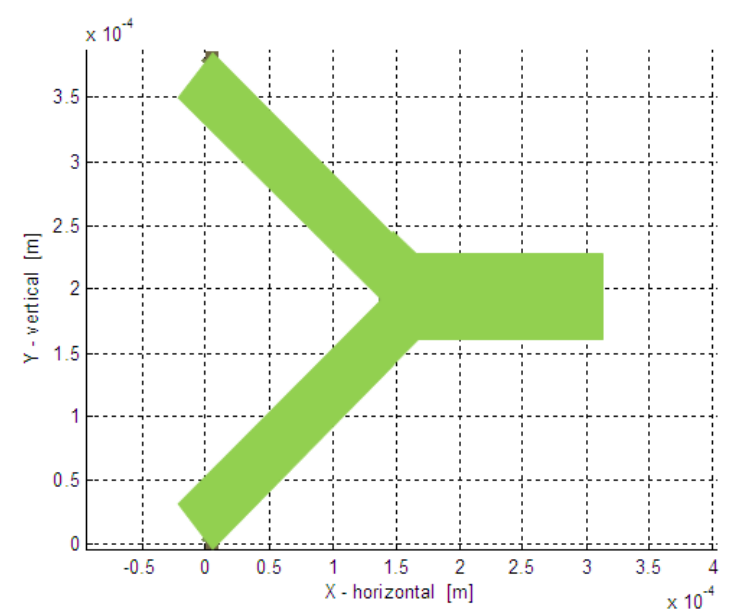

Figure. 6 Model 2 of the cantilever type MEMS switch. 


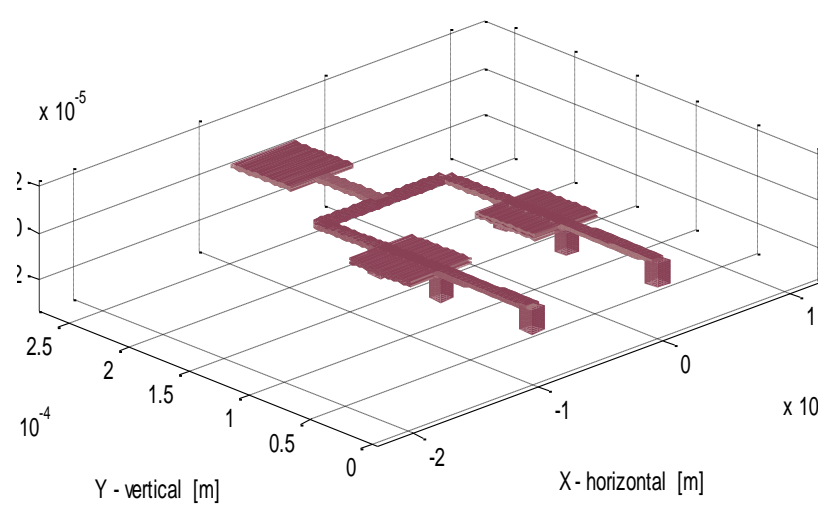

Figure. 7. Model 3 of the cantilever type MEMS switch.

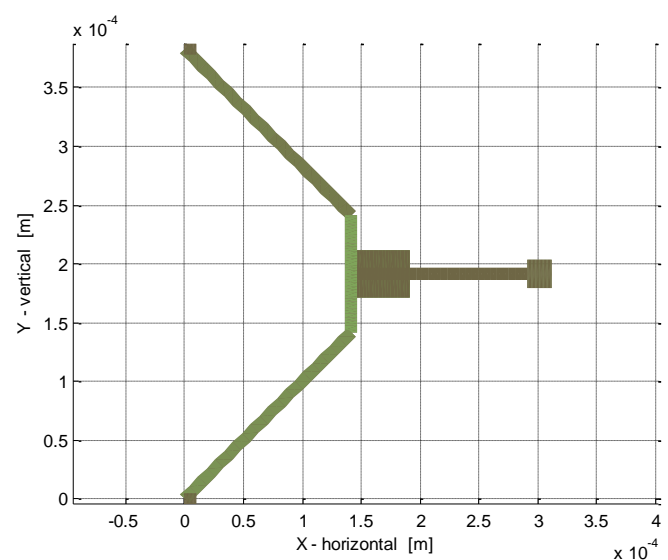

Figure. 8. Model 4 of the cantilever type MEMS switch.

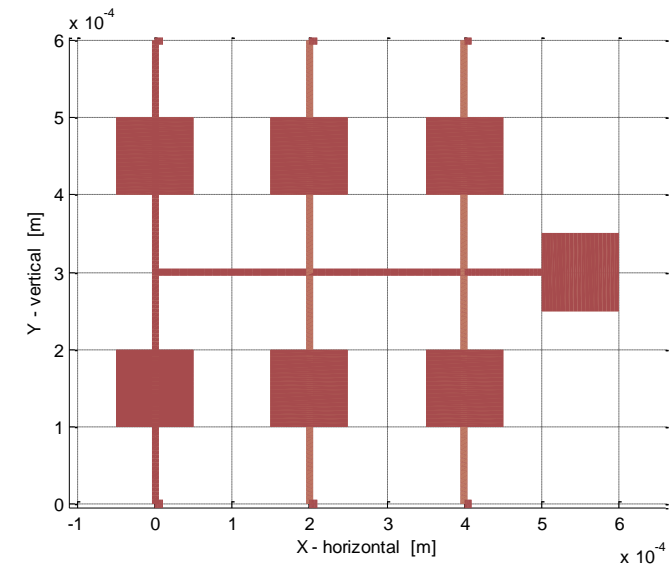

Figure. 9. Model 5 of the cantilever type MEMS switch.

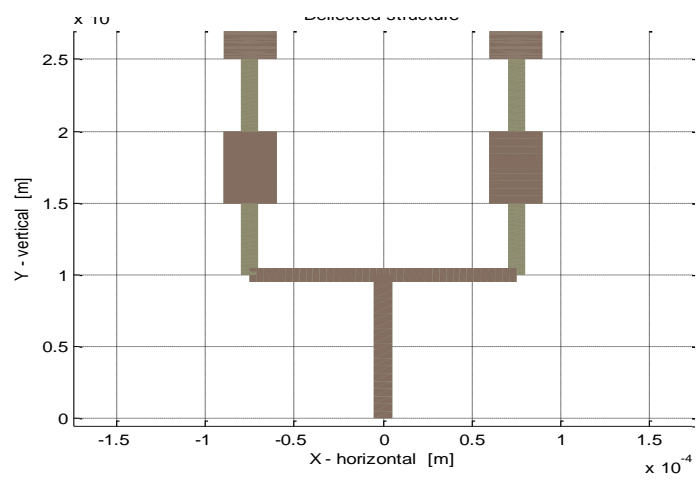

Figure. 10. Model 6 of the cantilever type MEMS switch.

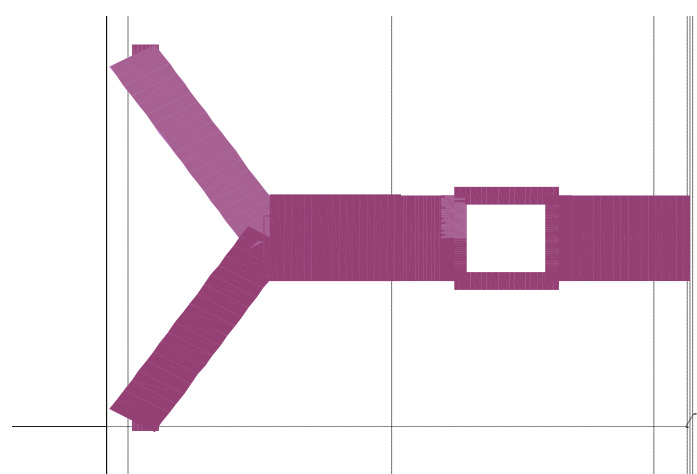

Figure. 11. Model 7 of the cantilever type MEMS switch.

Table (2) The structure Parameters

\begin{tabular}{|c|c|c|c|c|c|c|}
\hline Parameter & $\begin{array}{c}\text { Beam } \\
\text { Angle }\end{array}$ & $\begin{array}{c}\text { gap } \\
\text { Length }\end{array}$ & $\begin{array}{c}\text { gap } \\
\text { width }\end{array}$ & $\begin{array}{c}\text { Beam } \\
\text { width }\end{array}$ & $\begin{array}{c}\text { Extended } \\
\text { Beam } \\
\text { length }\end{array}$ & hole \\
\hline Value & $45^{\circ}$ & $50 \mu \mathrm{m}$ & $\begin{array}{c}40 \\
\mu \mathrm{m}\end{array}$ & $\begin{array}{c}10 \\
\mu \mathrm{m}\end{array}$ & $50 \mu \mathrm{m}$ & $40 \mu \mathrm{m}$ \\
\hline
\end{tabular}

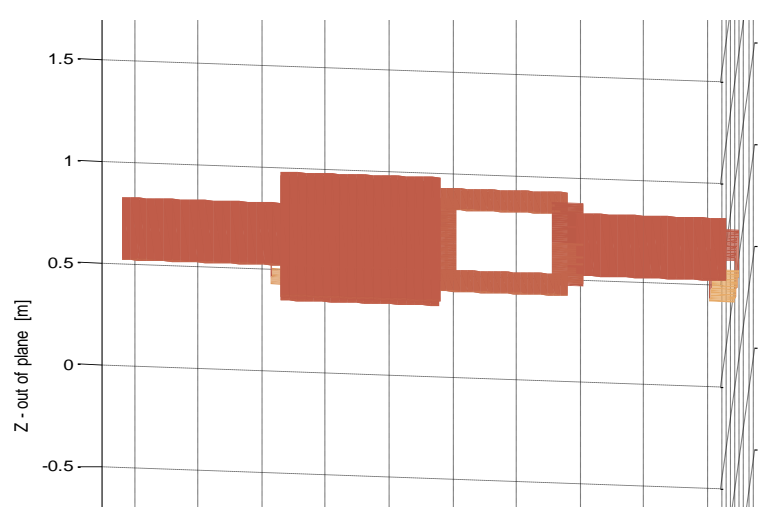

Figure. 12. Model 8 of the cantilever type MEMS switch.

Table (2) The structure Parameters

\begin{tabular}{|c|c|c|c|c|c|c|}
\hline Parameter & $\begin{array}{c}\text { Beam } \\
\text { Angle }\end{array}$ & $\begin{array}{c}\text { gap } \\
\text { Length }\end{array}$ & $\begin{array}{c}\text { gap } \\
\text { width }\end{array}$ & $\begin{array}{c}\text { Beam } \\
\text { width }\end{array}$ & $\begin{array}{c}\text { Extended } \\
\text { Beam } \\
\text { length }\end{array}$ & hole \\
\hline Value & 0 & $50 \mu \mathrm{m}$ & $\begin{array}{c}60 \\
\mu \mathrm{m}\end{array}$ & $\begin{array}{c}30 \\
\mu \mathrm{m}\end{array}$ & $100 \mu \mathrm{m}$ & $40 \mu \mathrm{m}$ \\
\hline
\end{tabular}

Trade Off (T.O)measure:

an introduced Trade-Off is taken as a new measure for MEMS switching to select the most probable frequency - voltage dependence, where

T.O = Switching Frequency / Driving Voltage

Table(6): Simulation Results

\begin{tabular}{|l|c|c|c|c|}
\hline Parameters & model & $\begin{array}{c}\text { Driving } \\
\text { Voltage } \\
(\mathrm{V})\end{array}$ & $\begin{array}{c}\text { Switching } \\
\text { Frequency } \\
(\mathrm{MHz})\end{array}$ & $\begin{array}{c}\text { Trade- } \\
\text { Off }\end{array}$ \\
\hline \multirow{4}{*}{$\begin{array}{c}\text { Proposed } \\
\text { Structures }\end{array}$} & 1 & 4.2 & 1037.4 & 247 \\
\cline { 2 - 5 } & 2 & 9 & 2533.7 & 281.52 \\
\cline { 2 - 5 } & 3 & 6.5 & 3002.4 & 461.91 \\
\cline { 2 - 5 } & 4 & 6.6 & 6657.1 & 1008.65 \\
\cline { 2 - 5 } & 6 & 4.6 & 1559.4 & 339 \\
\cline { 2 - 6 } & 7 & 4.4 & 8830 & 2006.82 \\
\cline { 2 - 5 } & 8 & 5.5 & 6185.2 & 618.52 \\
\hline
\end{tabular}




\section{CONCLUSION}

This paper investigates the geometrical parameters of the five MEMS structures that control the switching voltage to achieve a maximum frequency response for the switch at lower driving voltage. The structure of the proposed cantilever type MEMS switches indicates that the switch can operate with driving voltage of $4.4 \mathrm{~V}$ with maximum switching frequency of $8.83 \mathrm{GHz}$ best Trade-Off. These structures are suitable for radar antenna applications. The simulation results compared to previous MEMS switches design and show acceptable results.

\section{REFERENCES}

[1] Chiung-I Lee ; Tainan ; Chih-Hsiang Ko ; Huang, TsunChe,"Design of Multi-actuation RF MEMS Switch Using CMOS Process," 3rd International Conference on Microsystems, Packaging, Assembly \& Circuits Technology 2008. IMPACT 2008, 2008.

[2] Vijay K. Varadan, K. J. Vinoy, K. A. Jose." RF mems and their applications " A. Jose, Wiley, 2002

[3] Sahu, A.K. ; Sarkar, B.K.,"A novel low actuation voltage RF MEMS shunt capacitive switch," Applied Electromagnetics Conference (AEMC), 2009.

[4] Hatem Samaali, Fehmi Najar, Ali Naefeh, and Mohamed Masmoudi,"Novel Design of MEMS Ohmic RF Switch with Low Voltage Actuation,'International Conference on Circuits and Systems, 2009.

[5] Yanjue Gong, Li Zhang, Fu Zhao, Chunlin Meng, and Liang Lv,"Design Optimization of Cantilever Beam MEMS Swiitch," International Conference on Inductrial Mechatronics and Automation, 2009.

.[6] Sung-Jin, and Joseph C., "Piezoresistive Cantilever Performance-Part-II: Optimization," Journal of Micromechanical Systems Vol. 19 No. 1 February 2010.

[7] Mohamed Shalaby, Zhongde Wang, Linda L, and Brian D. Jensen,"Robust Design of RF MEMS Cantilever Switches Using Contact Physics Modeling," IEEE Tranaction in Inductrial Electronics Vol. 56, No. 4, April, 2009.

[8] David Chung, and Roland G.,"Reduced Size Low Voltage RF MEMS $X$ Band Phase Shifter Integrated on Multilayer Organic Package," IEEE Transaction on Components Packaging and manufacturing Technology, Vol. 2, No. 10, October 2012.

[9] Gregory Panaitov, Norbert Klien and Stefan Trellenkamp,"U-Saped Bimorph Microelectromechanical Cantilevers with Combined Thermal Electrostatic actuation,"Journal of Microwave Engineering, Article in press, 2012.

[10] Nazita Taghavi, and Hassan Nahvi,'Pull-in Instability of Cantilever and Fixed Fixed Nano Switches,:European Journal of Mechanics A/Solids Vol.41, 2013.

[11] Jason Vaughn Clark, Ningning Zhou, and K. S. J. Pister.MEMS Simulation using SUGAR v0.5. http://www.bsac.eecs.berkel.edu

[12] Saeid Afrang, Ghader Rezazadeh "Design and Simulation of Simple and Varying Section Cantilever and Fixed-Fixed End Types MEMS Switches", ICSE 2004 Proc. 2004, Kula Lumpur, Malysia, pp. 593-596.

[13] N. J. R. Muniraj, "MEMS based humidity sensor using Si cantilever beam for harsh environmental conditions," Microsystem Technologies, vol. 17, pp. 27-29, 2011.
[14] Don Klaitabtim and Adisorn Tuantranont, "Design Consideration and Finite Element Modeling of MEMS Cantilever for Nano-Biosensor Applications," 5th IEEE Conference on Nanotechnology Nagoya, Japan, July 2005,

[15] Haslina Jaafar, Fong Li Nan, Nurul Amziah Md Yunus, "Design and Simulation of High Performance RF MEMS Series Switch," RSM2011 Proc., 2011, Kota Kinabalu, Malaysia, pp. 349-353,

[16] N. Zhou, J. V. Clark, K. S. J. Pister, "Nodal Simulation for MEMS Design Using SUGAR v0.5." In 1998 International Conference on Modeling and Simulation of Microsystems Semiconductors, Sensors and Actuators Santa Clara, CA, April 6-8, 1998, pp. 308-313.

[17] J. V. Clark, N. Zhou, K. S. J. Pister, "MEMS Simulation Using SUGAR v0.5." In Proc. Solid-State Sensors and Actuators Workshop Hilton Head Island, SC, June 8-11, 1998, pp. 191-196.

[18] J. V. Clark, N. Zhou, K. S. J. Pister, "Modified Nodal Analysis for MEMS with Multi-Energy Domains." In International Conference on Modeling and Simulation of Microsystems, Semiconductors, Sensors and Actuators. San Diego, CA, March 27-29, 2000, pp. 31-34.

[19] J. V. Clark, N. Zhou, D. Bindel, L. Schenato, W. Wu, J. Demmel, K. S. J. Pister, "3D MEMS Simulation Modeling Using Modified Nodal Analysis." In Proceedings of the Microscale Systems: Mechanics and Measurements Symposium. Orlando, FL, June 8, 2000, pp. 68-75.

[20] Z. Bai, D. Bindel, J. V. Clark, J. Demmel, K. S. J. Pister, N. Zhou, "New Numerical Techniques and Tools in Sugar for 3D MEMS Simulation." In Technical Proceedings of the Fourth International Conference on Modeling and Simulation of Microsystems. Hilton Head Island, SC, March 19-21, 2001, pp. 31-34.

[21] J. V. Clark, D. Bindel, N. Zhou, S. Bhave, Z. Bai, J. Demmel, K. S. J. Pister, "Sugar: Advancements in a 3D Multi-Domain Simulation Package for MEMS." In Proceedings of the Microscale Systems: Mechanics and Measurements Symposium. Portland, OR, June 4, 2001.

[22] N. Zhou, B. Zhu, A. M. Agogino, K. S. J. Pister, "Evolutionary Synthesis of Microelectromechanical Systems (MEMS) Design." In Proceedings of ANNIE 2001: IEEE Neural Networks Council and Smart Engineering Systems Laboratory. ASME Press, Vol. 11, pp. 197-202. St. Louis, Missouri, Nov. 4-7, 2001.

[23] J. V. Clark, D. Bindel, W. Kao, E. Zhu, A. Kuo, N. Zhou, J. Nie, J. Demmel, Z. Bai, S. Govindjee, K. S. J. Pister, M. Gu, A. Agogino, "Addressing the Needs of Complex MEMS Design." To appear in MEMS 2002. Las Vegas, Nevada, January 20-24, 2002.

[24] J. V. Clark, D. Garmire, M. Last, J. Demmel. "Practical Techniques for Measuring MEMS Properties." Nanotech 2004, The Technical Proceedings of the Nano Science and Technology Institute, Boston, MA, March 7-11 2004, Vol. 1, pp. 402-405

[25] Internet site http://ee.hawaii.edu/ garmire/sugar/ SUGAR v3.1 